\title{
Peningkatan Kemampuan Kader Remaja Dalam Pengendalian Hipertensi Melalui Posyandu Remaja Parikesit \\ Ratna Lestari ${ }^{1}$, Miftafu Darussalam ${ }^{2}$, Fajriyati Nur Azizah ${ }^{3}$, Ferianto $^{4}$, Sriyati Sipora ${ }^{5}$ \\ 1,2,3Pendidikan Profesi Ners, Fakultas Kesehatan, Universitas Jenderal Achmad Yani Yogyakarta, Indonesia \\ ${ }^{4}$ Keperawatan (S1), Fakultas Kesehatan, Universitas Jenderal Achmad Yani, Yogyakarta, Indonesia \\ ${ }^{5}$ Perawat, Puskesmas Kalasan
}

e-mail: ${ }^{1}$ ratnalestarigg@gmail.com, ${ }^{2}$ nsdarus00@gmail.com, ${ }^{3}$ fajriyatinurazizah@ gmail.com, ${ }^{4}$ rm.jailani@gmail.com, ${ }^{5}$ sipora2020@gmail.com,

ABSTRAK Hipertensi dikenal dengan silent killer karena merupakan penyakit yang menyebabkan kematian tanpa disadari. Prevalensi hipertensi di Indonesia sebesar $34,11 \%$ pada usia penduduk $>18$ tahun. Persentase ini mengalami peningkatan dibandingkan tahun 2013 sebesar 25,8\%. Daerah Istimewa Yogyakarta menduduki peringkat ke 12 dengan jumlah prevalensi hipertensi tertinggi sebesar 32,86\%. Sejalan dengan data Profil Kesehatan Provinsi Yogyakarta yang melaporkan kasus hipertensi terbanyak di Kabupaten Sleman yaitu 12,10\% dengan penyumbang terbesarnya berda di Kecamatan Kalasan.

Hipertensi yang tidak dikelola dengan baik akan berlanjut pada penyakit kardio maupun vaskuler lainnya yang memberikan dampak pada kematian. Dibutuhkan pengendalian hipertensi melalui partisipasi aktif masyarakat atau pemberdayaan kader kesehatan. Pemberdayaan ini dilakukan dalam Upaya Kesehatan Bersumberdaya Masyarakat (UKBM) Posyandu Remaja Parikesit. Kegiatan pengabdian kepada masyarakat ini bertujuan untuk melatih kader remaja agar mempunyai pengetahuan dan keterampilan tentang hipertensi. Kegiatan pemberdayaan ini dilakukan dengan memberikan edukasi tentang hipertensi kepada kader remaja atau dikenal dengan parikesit, melatih kader menggunakan spigmometer digital agar dapat mengukur tekanan darah, dan mengajarkan cara mengisi buku raport hipertensi. Metode yang digunakan dalam pengabdian kepada masyarakat ini terdiri dari diskusi interaktif dan demonstrasi. Sebelum dan sesudah kegiatan, pengetahuan tentang hipertensi diukur dengan kuesioner pengetahuan hipertensi, sedangkan keterampilan diobservasi dengan lembar observasi pengukuran tekanan darah. Berdasarkan hasil evaluasi pelatihan kader didapatkan data tidak ada satupun kader remaja dengan hasil pengetahuan setelah edukasi lebih rendah daripada sebelum edukasi (0\%), 3 kader remaja berpengetahuan sama/ tetap $(17,7 \%)$, dan 14 kader remaja mempunyai pengetahuan yang lebih baik dari sebelum edukasi hipertensi $(82,3 \%)$. Nilai p menunjukkan 0,001 yang berarti pelatihan kader remaja memiliki pengaruh terhadap peningkatan pengetahuan tentang hipertensi. Selain itu keterampilan kader remaja mengalami peningkatan setelah diberikan pelatihan sebesar $70,5 \%$ dengan nilai $\mathrm{p} 0,000$.

KATA KUNCI: Posyandu Remaja; Hipertensi; Kader Remaja

ABSTRACT Hypertension is known as the silent killer due to the unrealize death of sufferer. Prevalence of hypertension in Indonesia is $34.11 \%$ for people aged more than 18 years of age. This percentage has increased compared to 2013 which was $25.8 \%$. DIY was ranked 12 th with a total prevalence of $32.86 \%$. In line of DIY Profile Data, it's stated that the most cases of hypertension are in Sleman Regency about $12.10 \%$ and the largest contributor to hypertension sufferers in Kalasan. 
Uncontrolled Hypertension has a severe effect or complication on cardio and vascular diseases that have an impact on death. Hypertension control is needed through active community participation or empowerment of health cadres. This empowerment is carried out in the Community Based Health Efforts (UKBM) of the Posyandu Remaja Parikesit. This community service activity aims to train youth cadres to have knowledge and skills about hypertension. This empowerment activity is carried out by providing education about hypertension to adolescent cadres or known as parikesit, training cadres to use digital sphygmomanometers to be able to measure blood pressure, and teaching how to fill out hypertension report cards. The method used in this community service consists of interactive discussions and demonstrations. Before and after this activity, hypertension knowledge is measured by questionaire, besides skill is observed by blood pressure measurement checklist sheet. Based on the results of the evaluation of cadre training, it was found that there was no single adolescent cadre with lower knowledge after education than before education (0\%), 3 youth cadres with the samelfixed knowledge $(17.7 \%)$, and 14 youth cadres had better knowledge than before hypertension education (82.3\%). The $p$ value shows 0.001 which means that the training of adolescent cadres has an effect on increasing knowledge about hypertension. In addition, 100\% of cadres have skilled in measuring blood pressure.

\section{KEYWORDS : Posyandu Remaja; Hypertension; Youth Cadre}

\section{Pendahuluan}

Hipertensi atau biasa disebut penyakit darah tinggi merupakan suatu keadaan tekanan darah seseorang yang melebihi batas normal $\geq 140 \mathrm{mmHg}$ untuk sistolik dan $\geq 90 \mathrm{mmHg}$ untuk diastolik. Hipertensi dijuluki sebagai the silent disease (penyakit tanpa gejala), hal ini karena penderita tidak menyadari bahwa dirinya telah mengidap penyakit hipertensi. Biasanya penyakit ini akan langsung menimbulkan kondisi yang sudah parah seperti stroke, serangan jantung, gagal jantung hingga gagal ginjal kronik [1].

Menurut data WHO (World Health Organization) tahun 2019 prevalensi hipertensi secara global sebesar $22 \%$ dari total penduduk dunia. Asia Tenggara berada pada posisi ke-3 yaitu dengan prevalensi sebesar $25 \%$ dari total penduduk [2]. Berdasarkan hasil Riskesdas dari Kementerian Kesehatan RI (2018) dilaporkan angka prevalensi hipertensi di Indonesia sebesar 34,11\% pada usia penduduk >18 tahun, prevalensi tersebut diperoleh dari pengukuran tekanan darah dan berdasarkan kriteria JNC VII [3]. Persentase ini meningkat dibandingkan tahun 2013 sebesar 25,8\%. Didukung oleh penelitian sebelumnya bahwa jumlah kasus penderita hipertensi di Indonesia diperkirakan mencapai sekitar 15 juta orang [4].

Daerah Istimewa Yogyakarta menduduki peringkat ke 12 dengan jumlah prevalensi 32,86\%. Berdasarkan Data Profil Kesehatan Provinsi Yogyakarta (2017) dilaporkan bahwa kasus hipertensi tertinggi berada di Kabupaten Sleman yaitu $12,10 \%$ [5]. Dinkes Kabupaten Sleman (2020) mencatat bahwa Kecamatan Kalasan sebagai penyumbang terbesar kasus hipertensi dibandingkan kecamatan lain di Kabupaten Sleman sebanyak 56.668 kasus. Berdasarkan hasil surveilans Program Indonesia Sehat dengan Pendekatan Keluarga (PIS-PK) indikator PIS-PK di 4 desa binaan Puskesmas Kalasan masih kategori di bawah cukup (39,7\%), dengan indikator permasalahan penderita hipertensi untuk melakukan pengobatan secara teratur yang masih rendah yaitu (IKS no.7) sebesar 26,6\%. Angka capaian tersebut sangat jauh dari angka targetnya $100 \%$.

Hipertensi harus dicegah dan diobati agar tidak meningkatkan angka kesakitan dan kematian di masyarakat. Pemerintah melalui Kemenkes RI telah mencanangkan 
pengendalian penyakit tidak menular (PTM) melalui program Cek kesehatan secara rutin, Enyahkan asap rokok, Rajin aktivitas fisik, Diit seimbang, Istirahat cukup, dan Kelola stres atau dikenal dengan CERDIK [6]. Program ini terintegrasi dalam kegiatan Posbindu PTM dan Posyandu remaja sebagai bentuk partisipasi aktif masyarakat untuk mengendalikan penyakit hipertensi.

Posyandu remaja merupakan bentuk upaya kesehatan bersumberdaya masyarakat (UKBM) guna memberdayakan masyarakat dan memberikan kemudahan dalam memberikan pelayanan kesehatan bagi remaja khususnya dan masyarakat pada umumnya untuk meningkatkan derajat kesehatan [3]. Pada tahap perkembangan remaja, secara kognitif remaja memiliki kemampuan belajar, memori, berpikir, dan bernalar. Remaja aktif mengembangkan kemampuan kognitif melalui informasi yang didapatkan sehingga dapat memunculkan ide baru [7]. Selain tahap perkembangan kognitif, tahap perkembangan sosial remaja yang lebih merasakan kenyamanan dalam kelompok/ peer dapat memberikan alasan bahwa kegiatan berkelompok tepat diterapkan pada remaja dengan melibatkan peran sektor terkait termasuk pelayanan kesehatan dan pendidikan dalam memberikan informasi dan arahan tentang kesehatan yang tepat. Kecamatan Kalasan memiliki 4 desa salah satunya desa selomartani. Penduduk usia remaja di Selomartani dengan jumlah, menjadi pertimbangan untuk dilatihnya kader remaja parikesit khususnya dalam mencegah dan mengendalikan hipertensi di masyarakat baik sehat, berisiko, dan sakit. Parikesit adalah kepanjangan dari putera-puteri kalasan sehat siaga terpadu. Parikesit merupakan branding kader remaja di kalasan yang dirintis dan dibina oleh Puskesmas Kalasan sejak 2015. Anggota Parikesit harapannya akan menjadi role model kesehatan bagi remaja lainnya di wilayah Kalasan, sehingga dapat meningkatkan potensi deteksi dini dan pencegahan masalah kesehatan.

Kegiatan pengabdian kepada masyarakat ini telah melalui tahap penguatan komitmen pada anggal 15 Maret 2021 sehingga tindak lanjut berupa pelatihan pengukuran tekanan darah dan menggunakan buku rapor hipertensi kepada kader posyandu remaja parikesit dilakukan dalam rangka meningkatkan keterampilan $\mathrm{k}$ ade $\mathrm{r}$ dalam mendeteksi hipertensi s ejak dini.

\section{Metode}

Kegiatan pengabdian ini dilaksanakan di Aula Kelurahan Selomartani, Kalasan Sleman. Kegiatan ini memperhatikan protokol kesehatan dan telah mendapatkan persetujuan dari Satgas Covid-19 Kepanewon Kalasan sehingga dihadiri kurang dari 30 orang. Total kader remaja yang hadir sebanyak 24 orang. Metode pelaksanaan meliputi tahap persiapan, pelaksanaan, dan evaluasi. Rincian tiap tahap adalah sebagai berikut:

\subsection{Tahap I (Tahap Persiapan)}

\subsubsection{Tahap perizinan}

Perizinan ditujukan ke Kelurahan Selomartani dan Kepanewon Kalasan. Surat izin ini mendapatkan balasan dari kedua instansi tersebut dan mengizinkan kegiatan dilaksanakan dengan menerapkan protokol kesehatan.

\subsubsection{Tahap persiapan}

Pada tahap persiapan, pengabdi dan tim mempersiapkan peralatan dan perlengkapan yang dibutuhkan terdiri atas spigmomanometer digital, lembar observasi skill mengukur tekanan darah, kuesioner pengetahuan kader tentang hipertensi, dan buku rapor hipertensi. 


\subsection{Tahap II (Tahap Pelaksanaan)}

\subsubsection{Tahap orientasi}

Ketua dan anggota tim pengabdian memperkenalkan diri kepada kader remaja. Dilanjutkan menjelaskan maksud dan tujuan kegiatan, kontrak waktu, serta menjelaskan mekanisme pelaksanaan kegiatan. Kader remaja juga memperkenalkan diri secara singkat kepada tim.

2.2.2 Tahap kerja

2.2.2.1.Memberikan pretest untuk memvalidasi pengetahuan awal kader remaja tentang hipertensi menggunakan kuesioner pengetahuan hipertensi dengan menggunakan link form aplikasi kuesioner.

2.2.2.2.Melakukan edukasi tentang konsep hipertensi dan teori pengukuran tekanan darah menggunakan metode ceramah, dibantu dengan powerpoint selama 40 menit

2.2.2.3.Demonstrasi cara mengukur tekanan darah menggunakan spygmomanometer digital

2.2.2.4.Melakukan redemonstrasi pengukuran tekanan darah pada sesama kader

2.2.2.5.Mengajarkan cara pengisian buku rapor hipertensi khususnya lembar pemantauan minum obat

2.2.2.6.Mengisi kuesioner posttest tentang pengetahuan hipertensi dengan link yang sama dengan pretest

\subsection{Evaluasi Pelatihan Kader Remaja}

Evaluasi kegiatan ini dilakukan dengan pengisian kuesioner posttest tentang pengetahuan hipertensi dan redemonstrasi cara mengukur tekanan darah. Dari 24 kader remaja yang mengisi kuesioner, hanya 17 yang mengisi secara lengkap baik pre maupun posttest sehingga 7 kuesioner di dropout. Adanya kegiatan pengabdian kepada masyarakat ini diharapkan dapat meningkatkan pengetahuan kader baik secara kognitif maupun keterampilan untuk mengendalikan tekanan darah pada kelompok masyarakat sehat, berisiko, maupun penderita hipertensi. Harapan kami kegiatan ini dapat memberdayakan kader remaja untuk berperan serta dalam meningkatkan kesehatan dan mencegah penyakit tidak menular khususnya hipertensi yang kasusnya semakin meningkat.

\section{Hasil dan Pembahasan}

Tabel 1. Karakteristik Kader Remaja Parikesit Mei 2021 (n=17)

\begin{tabular}{lcc}
\hline Karakteristik & Frekuensi & $\begin{array}{c}\text { Persentase } \\
(\mathbf{\%})\end{array}$ \\
Usia & & \\
\hline Minimum & 14 & \\
\hline Maksimum & 22 & \\
\hline Mean & 17,06 & \\
\hline Std. Deviasi & 2,46 & 88,2 \\
\hline Jenis Kelamin & & 11,8 \\
\hline Perempuan & 15 & 17,6 \\
\hline Laki-laki & 2 & 70,6 \\
\hline Pendidikan & 3 & 11,8 \\
\hline SMP & 12 & \\
\hline SMA & 2 & \\
\hline Perguruan Tinggi
\end{tabular}

Sumber: data primer, 2021

Tabel 1 menunjukkan bahwa rerata usia kader remaja adalah 17 tahun dengan 
perbedaan usia antar kader yaitu 2,46 tahun. Kader termuda berusia 14 tahun, sedangkan usia paling tua adalah 22 tahun. Mayoritas kader berjenis kelamin perempuan sebesar $88,2 \%$. Tingkat pendidikan kader didominasi dengan jenjang pendidikan SMA sebesar 70,6\%, sementara sebesar $17,6 \%$ kader dengan pendidikan SMP dan 11,8\% kader adalah mahasiswa.

Mengacu pada Kemenkes RI melalui buku Petunjuk Teknis Penyelenggaraan Posyandu Remaja mendefinisikan kader kesehatan remaja adalah remaja yang dipilih/ secara sukarela mengajukan diri dan dilatih untuk ikut melaksanakan upaya pelayanan kesehatan remaja bagi diri sendiri, teman sebaya, keluarga serta masyarakat [8]. Permenkes No 25 tahun 2014 menyebutkan usia remaja dimulai dari 10 sampai 18 tahun. Pada kegiatan pengabdian masyarakat ini, rerata usia kader kesehatan adalah 17 tahun. Masa remaja merupakan masa transisi dari anak menuju tahap yang lebih matang, dimana remaja mulai membutuhkan kemandirian, pencapaian identitas, dan menjadi lebih produktif [7]. Mereka lebih sering menghabiskan waktu bersama dengan teman sebayanya karena merasakan kenyamanan. Oleh karena itu dibutuhkan kelompok teman sebaya yang dapat mengajak dan mengembangkan diri pada kegiatan positif salah satunya posyandu remaja.

\section{Persentase Peningkatan Pengetahuan tentang Hipertensi}

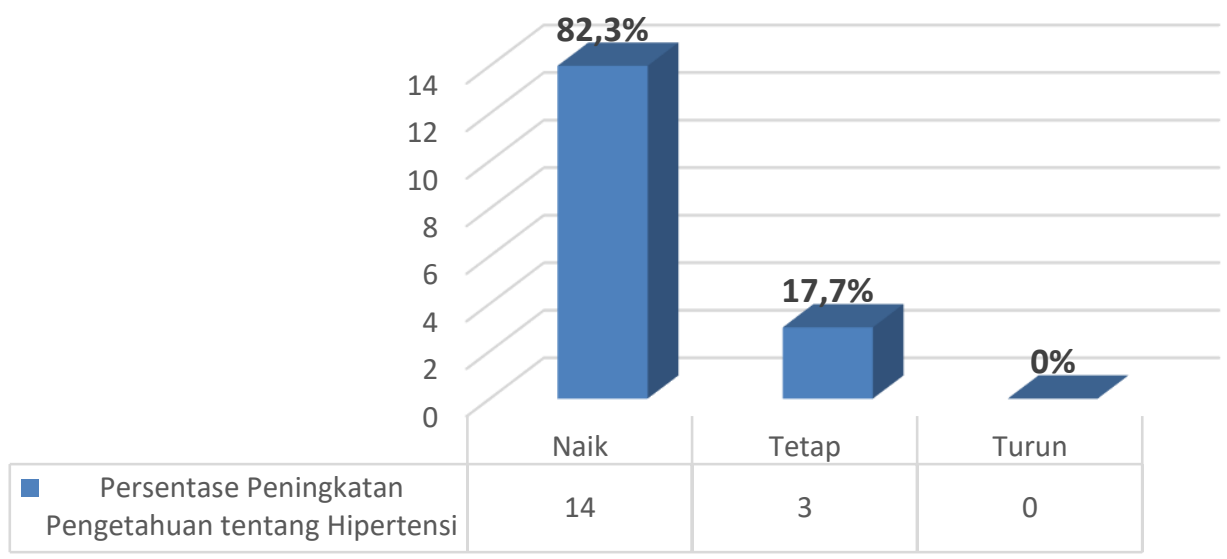

Gambar 1. Persentase Peningkatan Pengetahuan tentang hipertensi sebelum dan

sesudah pelatihan

Gambar 1 menunjukkan perbandingan pengetahuan sebelum dan sesudah edukasi hipertensi. Tidak ada satupun kader remaja dengan hasil pengetahuan setelah edukasi lebih rendah daripada sebelum edukasi (0\%), 3 kader remaja berpengetahuan sama/ tetap $(17,7 \%)$, dan 14 kader remaja mempunyai pengetahuan yang lebih baik dari sebelum edukasi hipertensi (82,3\%). Adanya peningkatan pengetahuan pada kader remaja dapat dipengaruhi oleh faktor internal dan eksternal [9]. Faktor internal diantaranya usia, pendidikan, dan pekerjaan. Rerata usia kader remaja dalam pengabdian masyarakat ini adalah 17 tahun, namun ada 3 orang kader dengan usia 22. Pada usia ini kompetensi dan tanggungjawab sudah mulai dilakukan oleh remaja. Didukung oleh penelitian sebelumnya bahwa semakin bertambahnya usia akan diikuti oleh kematangan pola pikir seseorang. Selain usia, pendidikan juga menjadi faktor yang memengaruhi pengetahuan. Mayoritas kader remaja berpendidikan SMA sebesar 70,6\% dan perguruan tinggi sebesar 11,8\%. Tingkat pendidikan akan menentukan cara pandang seseorang dalam menerima informasi yang didapat dalam hal ini adalah informasi tentang hipertensi [10]. 
Berdasarkan hasil analisis data, masih terdapat 3 orang kader remaja yang pengetahuannya tetap atau sama setelah diberikan edukasi kesehatan. Hal ini terjadi karena 3 orang kader tersebut mendapatkan hasil pretest dan posttest dengan nilai maksimal yaitu 10 yang merupakan nilai tertinggi.

Tabel 2. Pengetahuan kader remaja sebelum dan sesudah edukasi hipertensi

\begin{tabular}{|c|c|c|c|c|}
\hline & n & $\begin{array}{c}\text { Median } \\
\text { (minimum- } \\
\text { maksimum) }\end{array}$ & $\begin{array}{c}\text { Selisih } \\
\text { Median }\end{array}$ & $\begin{array}{c}\mathrm{P} \\
\text { value }\end{array}$ \\
\hline Pengetahuan & 17 & $7(1-9)$ & & \\
\hline edukasi & & & 3 & 0,001 \\
\hline Pengetahuan setelah edukasi & 17 & $10(3-10)$ & & \\
\hline
\end{tabular}

Sumber: data primer, 2021

Berdasarkan tabel 2 diketahui tingkat pengetahuan sebelum edukasi nilai minimal 1 dan maksimal 9 dengan nilai median 7. Sementara tingkat pengetahuan setelah edukasi nilai minimal 3 dan maksimal 10 dengan nilai median 10. Setelah dilakukan uji statistik menggunakan uji wilcoxon didapatkan nilai p $0,001<0,05$ maka secara statistik ada perbedaan tingkat pengetahuan kader remaja sebelum dan setelah diberikan edukasi tentang hipertensi. Hasil ini menunjukkan adanya perubahan pada pengetahuan kader remaja setelah diberikan edukasi kesehatan tentang hipertensi yang sesuai dengan harapan. Sejalan dengan hasil penelitian sebelumnya bahwa terdapat pengaruh pendidikan kesehatan tentang penatalaksanaan non farmakologi hipertensi terhadap tingkat pengetahuan kader dengan nilai p 0,007 pada kelompok intervensi [11]. Didukung oleh hasil pengabdian kepada masyarakat tentang pelatihan kader antihipertensi dimana terdapat peningkatan pengetahuan kader antihipertensi menjadi $87,27 \%$ setelah diberikan pelatihan [12]. Pelatihan merupakan suatu proses belajar mengajar terhadap pengetahuan dan keterampilan tertentu serta sikap agar semakin terampil dan mampu melaksanakan tanggungjawab berdasarkan pengalaman yang didapatkan sehingga akan terjadi perubahan perilaku [13]. Strategi yang digunakan dalam pelatihan salah satunya melalui pendidikan kesehatan yang bertujuan untuk memberikan informasi atau pesan kesehatan yang sesuai dan spesifik sehingga diharapkan dapat meningkatkan pengetahuan kader. Pemberian edukasi kesehatan tentang hipertensi meliputi definisi, faktor risiko, tanda dan gejala, komplikasi, pencegahan dan teori tentang pengukuran tekanan darah dengan metode ceramah ditambah dengan powerpoint dan buku rapor sebagai media edukasi.

Tabel 3. Keterampilan Kader Mengukur Tekanan Darah

\begin{tabular}{|c|c|c|c|c|c|}
\hline & & \multicolumn{2}{|c|}{$\begin{array}{c}\text { Keterampilan sesudah } \\
\text { pelatihan }\end{array}$} & \multirow{2}{*}{ Total } & \multirow[b]{2}{*}{$\mathrm{p}$} \\
\hline & & Terampil & $\begin{array}{c}\text { Tidak } \\
\text { Terampil }\end{array}$ & & \\
\hline \multirow{2}{*}{$\begin{array}{l}\text { Keterampilan } \\
\text { sebelum pelatihan }\end{array}$} & Terampil & 3 & 0 & 3 & \multirow{3}{*}{0.000} \\
\hline & $\begin{array}{l}\text { Tidak } \\
\text { terampil }\end{array}$ & 12 & 2 & 14 & \\
\hline Total & & 15 & 2 & 17 & \\
\hline
\end{tabular}

Sumber: data primer, 2021

Merujuk pada tabel 3 diketahui bahwa mayoritas kader remaja menjadi lebih terampil dalam mengukur tekanan darah setelah diberikan pelatihan sebanyak 12 
orang $(70,5 \%)$, tetap terampil sebelum dan sesudah pelatihan sebesar $17,6 \%$, dan $11,7 \%$ tetap tidak terampil dalam mengukur tekanan darah. Keterampilan mengukur tekanan darah diukur menggunakan lembar ceklist pengukuran tekanan darah dari buku panduan praktikum keperawatan dasar. Kader dikatakan terampil apabila semua langkah pada lembar ceklist dilakukan dengan benar. Keterampilan kader meningkat setelah diberikan pelatihan mengukur tekanan darah dengan nilai p 0,000. Sesuai dengan penelitian sebelumnya yang melaporkan peningkatan keterampilan kader posyandu menggunakan dacin sebesar 84,93\% [14]. Masih adanya kader remaja yang tidak terampil mengukur tekanan darah dikarenakan tidak semua langkah dilakukan oleh kader, diantaranya kader belum menyampaikan hal apa saja yang tidak boleh dilakukan saat pengukuran tekanan darah, kurang tepat dalam pemasangan manset masih ada yang terlalu ke atas dan ke bawah belum sejajar jantung, dan selang manset belum berada ditengah lengan.

Posyandu remaja parikesit merupakan bentuk Upaya Kesehatan Bersumberdaya Masyarakat (UKBM) yang salah satu kegiatannya adalah pengendalian penyakit tidak menular. Pada pelatihan kader, pengabdi dan tim tidak menemukan kendala yang berarti karena mayoritas kader memiliki motivasi dan antusiasme yang tinggi untuk mengikuti pelatihan dari awal hingga akhir dalam rangka meningkatkan pengetahuan dan keterampilan mereka untuk mencegah penyakit tidak menular. Usia kader yang tergolong muda dan pengakuan terhadap keberadaan mereka di masyarakat menjadi kekuatan untuk keberlanjutan kegiatan ini.

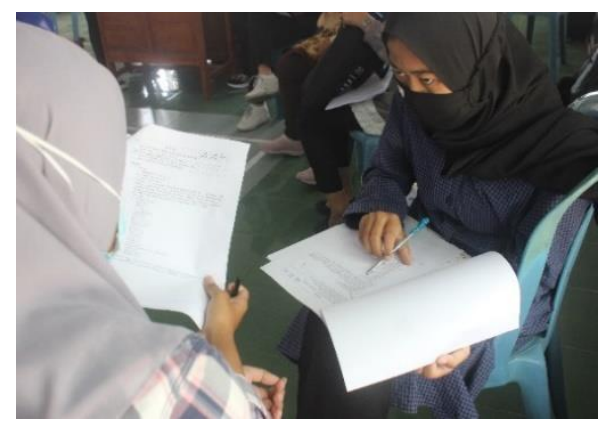

(a)

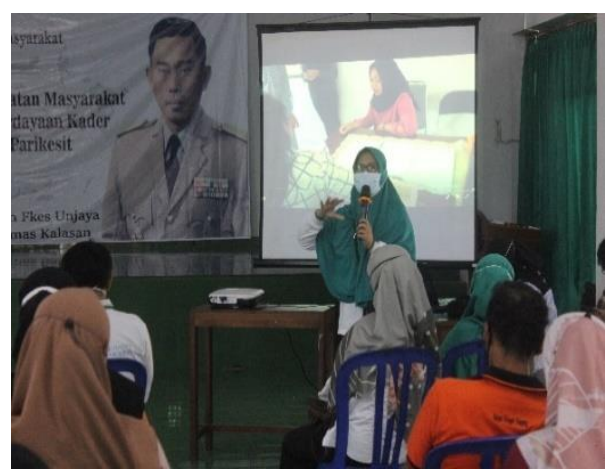

(c)

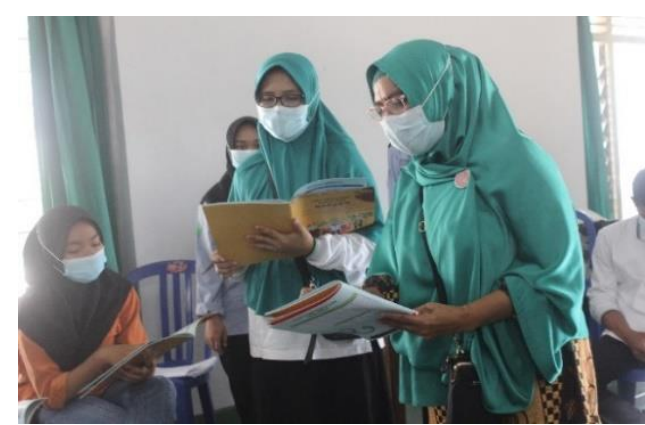

(b)

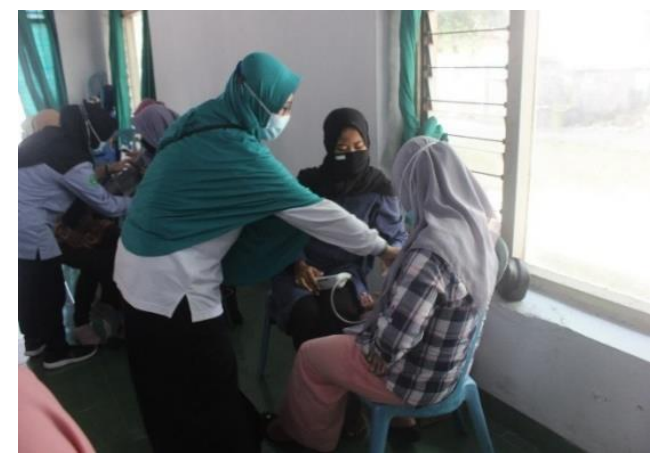

(d)

Gambar 2. Pretest (a), Edukasi tentang hipertensi (b) (c), Evaluasi redemonstrasi pengukuran tekanan $(\mathrm{d})$ 


\section{Kesimpulan}

Berdasarkan ketercapaian kegiatan pengabdian kepada masyarakat didapatkan hasil bahwa pengetahuan dan keterampilan kader remaja pada konsep hipertensi dan pengukuran tekanan darah meningkat setelah diberikan pelatihan. Oleh karenanya dibutuhkan dukungan dari tokoh masyarakat setempat dan puskesmas kalasan baik secara anggaran maupun pendampingan untuk mengaplikasikannya pada semua kelompok umur di masyarakat baik pada kelompok sehat, berisiko, maupun yang sudah menderita hipertensi sehingga pengendalian hipertensi bisa dicapai.

\section{Ucapan terima kasih}

Kami mengucapkan terima kasih kepada kader remaja Desa Selomartani yang telah bersedia untuk dilatih. Ucapan terima kasih kami sampaikan kepada tim dari Puskesmas Kalasan, Kepanewon Kalasan, dan Kelurahan Selomartani atas izin dan dukungan terlaksananya kegiatan ini. Selain itu kami sampaikan terima kasih kepada BEM Unjaya yang telah membantu terselenggaranya kegiatan dan Fakultas Kesehatan Universitas Jenderal Achmad Yani Yogyakarta yang telah memberikan bantuan dana untuk pelaksanaan pengabdian kepada masyarakat.

\section{Daftar pustaka}

[1] W. Kurniawati; Widiatie, "Pengaruh Pendidikan Kesehatan Terhadap Kepatuhan Diet Pada Penderita Hipertensi," vol. 7, no. 1, pp. 1-7, 2016.

[2] WHO, "Non-communicable Diseases: Contry Profiles 2018," Geneva, 2018. doi: 10.5005/jp/books/11410_18.

[3] Kemenkes RI, "Riskesdas 2018," Jakarta, 2018. [Online]. Available: http://labdata.litbang.kemkes.go.id/images/download/laporan/RKD/2018/L aporan_Nasional_RKD2018_FINAL.pdf.

[4] R. Lisiswanti and D. N. A. Dananda, "Upaya Pencegahan Hipertensi," J. Major., vol. 5, no. No 3, September, pp. 50-54, 2016, [Online]. Available: http://jukeunila.com/wp-content/uploads/2016/12/Dea-Nur-AuliaDananda.pdf.

[5] Dinas Kesehatan DIY, "Profil Kesehatan D.I Yogyakarta tahun 2018," Yogyakarta, 2018.

[6] D. Y. N. M. Defri Mulyana, Juhrodin, "Jurnal Pengabdian Siliwangi Jurnal Pengabdian Siliwangi Volume 5 , Nomor 1, Tahun 2019 P-ISSN 24776629," vol. 5, pp. 16-18, 2019.

[7] C. . Edelman, C.L \& Mandle, Health Promotion throughout Life Span, 8th editio. Missouri: Mosby, 2010.

[8] Kemenkes, Petunjuk Teknis Penyelenggaraan Posyandu Remaja. Jakarta: Kemenkes RI, 2018.

[9] A. E. Id et al., "An exploratory study on the quality of patient screening and counseling for hypertension management in Tanzania," pp. 1-13, 2020, doi: 10.1371/journal.pone.0227439. 
[10] H. Legido-quigley et al., "Patients ' experiences on accessing health care services for management of hypertension in rural Bangladesh , Pakistan and Sri Lanka: A qualitative study," pp. 1-23, 2019, doi: 10.1371/journal.pone.0211100.

[11] T. A. . Nekada, C; Mahendra, I.G; Rahil, N.H; Amigo, "Pengaruh Pendidikan Kesehatan Tentang Penatalaksanaan Non Farmakoterapi Hipertensi Terhadap Tingkat Pengetahuan,”vol. 3, no. 2, pp. 200-209, 2020.

[12] Safitri \& Lilfitriyani, "Pelatihan Kader Antihipertensi Sebagai Upaya Menurunkan Angka Hipertensi di Kabupaten Bojonegoro," J. Kreat. Pengabdi. Kpd. Masy., vol. 3, pp. 401-408, 2020.

[13] S. Notoatmodjo, Promosi Kesehatan dan Perilaku Kesehatan. Jakarta: Rineka Cipta, 2012.

[14] Y. Laraeni and A. Wiratni, "Pengaruh Penyegaran Kader Terhadap Pengetahuan Dan Keterampilan Kader Posyandu Menggunakan Dacin Di Wilayah Kerja Puskesmas Dasan Cermen Kecamatan Sandubaya Kota Mataram," Media Bina Ilm., no. 1978, pp. 44-52, 2014, [Online]. Available: http://www.lpsdimataram.com/phocadownload/Juli-2014/7-pengaruh penyegaran kader terhadap pengetahuan dan keterampilan kader-yuli laraeni.pdf. 